\title{
Gallium Ga 68 F(ab')2-Trastuzumab
}

National Cancer Institute

\section{Source}

National Cancer Institute. Gallium Ga 68 F(ab')2-Trastuzumab. NCI Thesaurus. Code C74033.

A radioimmunoconjug ate consisting of a trastuzumab fragment labeled with the positron-emitting radioisotope gallium Ga 68 with radioisotopic and antibody activities. Upon administration, Ga-68-labeled F(ab')2-trastuzumab may bind to HER2-positive tumor cells, allowing radioimmunolocalization with positron emission tomography (PET). Trastuzumab is a recombinant humanized monoclonal antibody that selectively binds to the extracellular domain of human epidermal growth factor receptor 2 (HER2), overexpressed by many adenocarcinomas, particularly breast adenocarcinomas. 